\title{
LOUCURA E CIDADE: CENAS BIOPOLÍTICAS \\ E INCURSÕES (DES) INSTITUCIONALIZANTES
}

\author{
Ana Karenina Arraes Amorim $\star$ \\ Magda Dimenstein $\star \star$
}

\section{ReSUMO}

Neste artigo, partimos do pressuposto de que a relação loucura-cidade serve como analisador do processo de desinstitucionalização em saúde mental e procuramos indicar os eixos disciplinares e biopolíticos em operação nesse campo. Para tanto, analisamos algumas cenas urbanas e certos acontecimentos que acompanhamos numa pesquisa acerca das práticas de cuidado no âmbito de um Serviço Residencial Terapêutico (SRT). E, com base no reconhecimento dos modos de operação do biopoder na relação loucura-cidade, procuramos argumentar que as formas de resistência aos manicômios biopoliticamente configurados na contemporaneidade devem operar macro e micropoliticamente por meio de "lutas em rede".

Palavras-chave: loucura; cidade; desinstitucionalização; saúde mental.

\section{Madness ANd City: BIPOLITICS SCENES AND (DIS) INSTITUTIONALIZING INCURSIONS}

\begin{abstract}
On this article, we start from the assumption that the relation town-madness serves as an analyzer of the deinstitutionalization process in mental health and we seek to indicate the disciplinary and biopolitical borders in operation in this field. For such, we analyze some urban scenes and certain events which we follow in a research about the care practices within a Therapeutic Residential Services (TRS). And, based on the recognition of biopower operation modes in the relation town-madness, we are willing to argue that the resistance forms of biopolitically configured asylums in contemporary should operate macro and micro politically through "struggles in network".

Keywords: madness; town; deinstitutionalization; mental health.

^Doutora em Psicologia Social pela Universidade Federal do Rio Grande do Norte. Professora do Departamento de Psicologia da Universidade Federal do Rio Grande do Norte. Endereço: UFRN, CCHLA, Departamento de Psicologia, Campus Universitário - Lagoa Nova. CEP 59.078-970. Natal, RN - BR. E-mail: akarraes@gmail.com

$\star \star$ Doutora em Saúde Mental pela Universidade Federal do Rio de Janeiro. Professora do Departamento de Psicologia da Universidade Federal do Rio Grande do Norte. Pesquisadora do CNPq. Endereço: UFRN, CCHLA, Departamento de Psicologia, Campus Universitário - Lagoa Nova. CEP 59.078-970. Natal, RN - BR.

E-mail:magda@ufrnet.br
\end{abstract}




\section{INTRODUÇ̃̃o}

A reforma psiquiátrica brasileira como processo ético, social e político de desinstitucionalização de saberes, discursos e práticas psiquiátricas redutoras da loucura à doença mental, enfrenta uma série de impasses e desafios. Quando consideramos o Serviço Residencial Terapêutico (SRT) - recente equipamento de cuidado configurado como um híbrido de serviço de saúde e casa e destinado a pessoas comhistória de longa internação em hospital psiquiátrico e abandono social - alguns desses impasses e desafios ficam mais evidentes. Dentre eles, destacamos as dificuldades na construção da vida e da cidadania dos moradores desse dispositivo na vida das grandes cidades.

$\mathrm{Na}$ compreensão dessas dificuldades, é preciso considerar tanto a existência concreta do manicômio, sustentada por um poder disciplinar de ordenação da vida, quanto a presença de uma "lógica manicomial" que participa dos processos de subjetivação na contemporaneidade, sustentada por uma biopolítica que regula a vida na cidade em diferentes níveis. Assim, considerando a relação loucura e cidade como analisador do processo de desinstitucionalização, procuramos neste artigo indicar esses dois eixos de poder em operação a partir da análise de algumas cenas urbanas que realizamos numa pesquisa acerca das práticas de cuidado no âmbito do SRT. ${ }^{1}$ E, por fim, com base no reconhecimento dos modos de operação do biopoder na contemporaneidade, procuramos argumentar que as formas de resistência aos manicômios biopoliticamente configurados na contemporaneidade devem operar mediante aquilo que Hardt e Negri (2005, p. 116) chamam de "lutas em rede".

\section{O MANICÔMIO NA CIDAdE E A LOUCURA LONGE DE NÓS: É FÁCIL PERCEBER OS "HOMENS DE LATA" PRODUZIDOS PELA PSIQUIATRIA!}

$\mathrm{Na}$ varanda de um apartamento na cidade do Recife, no bairro da Tamarineira, podemos olhar para o pátio interno do Hospital Ulisses Pernambucano, um grande hospital psiquiátrico, inaugurado em 10 de janeiro de 1887. Estávamos eu e uma menina de dois anos observando alguns internos simplesmente vagando pelo grande terreno repleto de mangueiras e muito vazio. O contraste entre a vida no interior do hospital e seu entorno efervescente na cidade era notável. Impressionava como aqueles centenários muros separavam duas realidades. Dirijo-me à menina $\mathrm{e}$ digo: "Olha, ali é onde moram os doidinhos". Ela olha para mim com estranheza e diz: "É não, não é [sic] os doidinhos não! Eles são os homens de lata!" e reproduz o movimento robótico dos "homens de lata" que via nos corpos daqueles internos e que lhe trouxeram à lembraça os da clássica história do Mágico de $\mathrm{Oz} .^{2}$

No uso do termo "doidinhos", em referência aos personagens como o "bobo", o "lelé da cuca", o "maluquinho" das brincadeiras e contos infantis, há a designação de uma face cômica, desejante e "produtiva" da loucura e da vida em seus excessos. No entanto, ao apelar para esse uso somos advertidas pela menina de que esta não é a face da loucura que se revela. O que estava evidente era a mortificação, a captura das almas que ali circulavam. Pudemos, então, 
constatar como é fácil perceber a falta de "coração" naqueles corpos de "homens de lata" que caminhavam no pátio do hospital psiquiátrico. Como é evidente (até para uma criança de dois anos!) a falta de desejo, de "sopro de vida" (sentido lato do radical grego psychè) naqueles corpos anestesiados por medicamentos e institucionalização. São os "homens de lata" produzidos historicamente pela psiquiatria que protagonizam (ou melhor, agonizam!) cenas como estas ainda tão comuns em nosso país. Cenas nas quais a presença dos muros manicomiais indica a separação entre a vida efervescente num grande centro urbano e, nele, a mortificação da vida no interior do asilo.

Como, então, essas faces da loucura se configuram? Que sentidos a loucura vai assumindo e que práticas e discursos se têm sobre ela na cidade? Como esses "homens de lata" foram inventados e aparecem no cenário contemporâneo? Tais questões nos exigem um diálogo com a loucura e seus sentidos e imagens a partir do que fomos convocados a "ver e dizer" em nosso encontro com a experiência de um serviço residencial terapêutico. Como um dispositivo desinstitucionalizante, o SRT tem por objetivo desconstruir o processo de conversão dessas pessoas hospitalizadas em "homens de lata", possibilitando que o "sopro de vida" tenha lugar e movimento na cidade, que o desejo siga desejando nessas vidas marcadamente anestesiadas pela institucionalização. E, nesse contexto, é preciso pensar sobre essa desconstrução e de que forma os "homens de lata" e os manicômios ainda se fazem presentes ali e em cada um que procura operar esse processo e se dispõe a produzir diferença.

A imagem da "loucura-doença mental" diz das capturas operadas pela tradição crítica da psiquiatria, da racionalidade moderna e dos discursos e práticas produzidos historicamente e que forjaram uma figura estereotipada e entorpecida para aqueles que "escapam" aos limites dessa racionalidade, como Foucault (1978) nos fez ver. São figuras como estas, marcadas por longos anos de institucionalização num hospital psiquiátrico, que chegam à residência terapêutica para "aprender a viver fora do hospital, para ter uma vida como gente!" - como nos afirma uma das técnicas que acompanharam os moradores na transição do hospital para a casa. Mas, como tais figuras da loucura foram produzidas ao ponto de essas pessoas terem "desaprendido a viver como gente"? Que saberes e poderes produzem esta figura?

Aprendemos com Foucault (1981) que, com o advento da modernidade, estabeleceu-se uma oposição (e não mais apenas uma relação) entre razão e desrazão e a valorização da racionalidade que funde os conceitos de loucura e desrazão como signos negativos e objetos de exclusão. Dentro do paradigma moderno, configura-se a "forma-Homem" padrão, o indivíduo, sujeito do conhecimento cartesiano, pautado no modelo hegemônico da racionalidade científica (DELEUZE, 1988). ${ }^{3}$ E é nesse paradigma que fundamenta os princípios burgueses de ordenação social e produção de riquezas das cidades, que são produzidos discursos e práticas de internação e exclusão relativos à loucura que ganha o estatuto de problema social, sendo percebida "no horizonte social da pobreza, da incapacidade para o trabalho, da impossibilidade de integrar-se no grupo; momento em que começa a inserir-se no texto dos problemas da cidade" (FOUCAULT, 1978, p. 78). Nesse 
contexto, erguem-se os chamados "Hospitais Gerais" na Europa do século XVII, cuja versão brasileira é a Santa Casa de Misericórdia no século XVIII. Como locus de exclusão dos pobres de toda sorte, dos que excedem os limites da razão e não respondem aos ideais capitalistas de então, esses estabelecimentos consistem em depósitos de massas de excluídos, nos quais a loucura é silenciada e dispersa.

Além do estatuto de problema social, a loucura adquire historicamente o estatuto de doença em relação ao qual são estruturados novos arranjos de controle social e jurídico aliados aos argumentos médicos. A psiquiatria pineliana separa a loucura da massa desrazoada, miserável e culpada e a reconhece em sua dignidade como doença. Assim, esse juízo por parte da "razão" coloca entre parênteses o parentesco entre loucura e miséria, circunscrevendo a loucura ao seu domínio "humanitário", como nos diz Basaglia (2005a, p. 263):

$\mathrm{O}$ que antes era aceito como uma das possibilidades do humano torna-se agora objeto de uma piedade e de uma compreensão em que a responsabilidade pelo ato é imputada à desrazão, e não mais ao indivíduo, do qual, porém, a razão se apropria no momento mesmo em que o desresponsabiliza.

Desse modo, a loucura e o louco, dominados pelas amarras da racionalidade, são silenciados, objetificados, excluídos e privados de desejos pelos valores burgueses. Foi essa aposta da psiquiatria na higiene e na ordem que tutela os loucos e os destitui como cidadãos, impedindo-os de circular na cidade. É com o argumento de que irá restituir a possibilidade de serem "outra vez cidadãos" que tem lugar o tratamento psiquiátrico e moral pineliano.

Inaugurado com base em princípios "humanitários" e científicos que "libertavam" os loucos como socialmente incapazes e conduziam a loucura a um tratamento moral diferenciado, punindo o indivíduo inteiro (BASAGLIA, 2005b), o hospital psiquiátrico constitui uma estrutura na qual a medicina vai exercer seu poder a partir de um "regime disciplinar" (FOUCAULT, 1988). Localizada no corpo, como desvio e patologia da natureza, a loucura é analisada, dissecada e tipificada em nosografias que são desenvolvidas para ordenar e organizar o tratamento, impedindo a "mistura" e o "contágio" entre as diferentes formas de adoecimento mental. O regime disciplinar, assim, marca as instituições psiquiátricas com esse sistema de domesticação e é responsável pela normalização do corpo através de uma "anátomo-política do corpo" (FOUCAULT, 1988, p. 131), de um conjunto de técnicas de poder que incide sobre o corpo individual, atuando em cada detalhe dos gestos, dos movimentos, do espaço e do tempo de modo a esquadrinhá-lo para aumentar-lhes a força útil na lógica produtiva do capital. Assim sendo, nessas instituições os corpos passam por um processo de disciplinarização, de modo que a vida moralmente aceitável seja restabelecida entre aqueles que desviavam, excediam e ameaçavam a "fôrma-homem" na cidade burguesa.

No Brasil, a história da psiquiatria é "a história de um processo de asilamento; é a história de um processo de medicalização social" (AMARANTE, 1994, p. 74), tendo em vista que a psiquiatria aparece desenhada num projeto de 
reordenamento do espaço urbano a partir da chegada da família real no Brasil, há 200 anos, o que produziu importantes modificações de ordem social, política e econômica em nosso país. O hospital psiquiátrico brasileiro é erguido sob um regime disciplinar e sustentado pelos ideais positivistas que organizam a vida social de então e que são, por assim dizer, importados da vida europeia e suas instituições. Com uma diferença cronológica em relação à realidade europeia, o hospital psiquiátrico brasileiro é erguido num contexto em que operam não apenas o regime disciplinar de controle dos corpos individuais, mas também outra tecnologia de poder que se integra à disciplina, uma tecnologia que Foucault (1999) vai chamar de biopolítica. ${ }^{4}$

A tecnologia biopolítica caracteriza-se pela gestão da vida incidindo já não mais sobre os indivíduos (como no sistema disciplinar), mas sobre a população que passa a ser controlada, regulada em seus processos biológicos (tais como a reprodução, a natalidade, a mortalidade e o nível de saúde). Há, então, uma segunda ordem de poder que é homogeneizante, uma vez que forma "uma massa global, afetada por processos de conjunto que são próprios da vida" (FOUCAULT, 1999, p. 289).

Os hospitais psiquiátricos, por sobreposição desses eixos do biopoder que neles atuam, a partir do século XIX, têm uma dupla função de normalização: controlar os corpos individuais mentalmente perturbados, disciplinando-os por meio de uma "anatomo-política do corpo", e proteger a população da desordem que tais corpos podem produzir na vida citadina, regulamentando-a através de uma "biopolítica da população" (FOUCAULT, 1988, p. 131).

É com esse poder sobre a vida que a psiquiatria "não se limita a estabelecer modelos ideais de comportamento individual, [mas sustenta uma ideologia segundo a qual ela deve] operar a reprodução ideal do conjunto social que se aproxima de uma concepção modelar de natureza humana" (AMARANTE, 1994, p. 78). Nessa "concepção modelar" do humano não cabem loucos, pobres e negros que representam a escória social e precisam, então, ser higienicamente banidos do espaço social. Constitui-se, assim, uma psiquiatria com características marcadamente racistas e eugênicas, em relação às quais os movimentos de reforma psiquiátrica atuais fazem frente. Psiquiatria esta que persiste e apresenta-se ainda hoje como uma forte e velha senhora na vida dos asilos brasileiros fincados no urbano das cidades brasileiras, tal como constatamos ao lado da menina. Perguntamo-nos, então, como operam hoje estas tecnologias de poder sobre a vida no contexto da cidade na vida de pessoas que, marcadas por longos processos de institucionalização e medicalização, inventam a vida fora do hospital? Que resistências aos poderes constituídos pela "velha senhora" são estas?

\section{A loucura na Cidade e o manicômio em nós. Por Que vias Resistir?}

Para pensarmos a respeito dos regimes de poder em jogo na cidade, precisamos atentar para os movimentos da vida contemporânea, para os nossos modos de subjetivação no cotidiano. Quando dirigimos nosso olhar para tais movimentos, percebemos que a concepção crítica da loucura persiste e ganha proporção, apesar 
de seus evidentes e violentos efeitos e dos movimentos políticos da luta antimanicomial e suas conquistas. Poderíamos dizer que não apenas aquelas imagens e sentidos da "loucura-doença mental" se reproduzem, mas que também corremos o risco de perdermos a possibilidade de experimentar a face da "loucura-desrazão", como nos adverte Foucault (2006, p. 210), numa espécie de "profecia" segundo a qual tende a se esvaziar a ligação entre os signos loucura e doença, colocando na cena contemporânea o signo doença mental cada vez mais próximo das afecções orgânicas, tornando-o passível de controle e cura. Assim, apagar-se-ão os resquícios disruptivos e transgressivos presentes no signo "loucura", de modo que estão cada vez mais evidentes os homens de lata produzidos pela psiquiatria!

Tais sentidos e imagens da loucura-doença mental vão revelando sua força e intensidade no cotidiano de todos nós. Sua presença revela-se a cada vez nos discursos e práticas de vigilância, de controle dos excessos, de nomeação da patologia, de classificação, de ajustamento do comportamento a uma normalidade "desejada" e consequente homogeneização das subjetividades.

Analisemos, então, duas cenas destacadas nos quadros abaixo por meio de três vetores: 1) a presença dos manicômios na vida contemporânea; 2) as marcas que essa presença produz; e 3) os mecanismos que a sustentam.

\section{CENA UM: LOUCOS PASSEIAM NUM SHOPPING}

Numa entrevista, uma das técnicas do SRT que acompanharam os moradores ex-internos nos fala do primeiro "passeio" pela cidade dos moradores no período de transição do hospital psiquiátrico para a residência da seguinte maneira:

O primeiro passeio foi pra o shopping. Não sei por que a gente escolheu o shopping, mas... nós fechamos o shopping literalmente! (risos) Pelo menos nos olhares nós fechamos. Todos os seguranças foram acionados, os rádios ligados, observando a gente. [Mas como se percebia que eram internos de um hospital psiquiátrico?] Ah, tinham alguns que ainda usavam a farda do JM [hospital psiquiátrico]. [...] Foi muito interessante por que quando eles olhavam pras vitrines admirados. E alguns diziam: porque que eu não posso ter uma roupa dessas? Como é bonito! E queriam pegar nas pessoas que passavam. Alguns viam as crianças e queriam pegar nas crianças num ato carinhoso, mas as pessoas recusavam. E aí na praça de alimentação, num público maior e eles daquele jeito comendo com a mão. Aqueles gestos assim... que o shopping parava olhando. E a gente percebia mesmo os seguranças todos em alerta (A., técnica da SMS, em entrevista no dia 24/01/2007, informação verbal) ${ }^{5}$

A cena mostra que as marcas da institucionalização e a lógica manicomial em operação vão-se revelando em sua extensão e intensidades. Corpos ainda animalizados, entorpecidos e enlatados em "espécimes nosográficas" e vestes 
hospitalares não passam despercebidos. Convocam o olhar, suscitam o medo e a recusa. Sua estranheza escancara a diferença. Perambulando no templo do consumo, a loucura, em sua face trágica, é injusta e violentamente pobre e impotente.

A lógica manicomial, produzida historicamente, é aí reforçada por valores tipicamente capitalísticos, faz mover a máquina desejante e opera sob a forma da recusa, da inacessibilidade ao consumo pelos loucos pobres (os habitantes de hospitais), do olhar vigilante e temeroso presentes no shopping ou em qualquer espaço na vida contemporânea quando a diferença e a desigualdade social se apresentam de modo mais radical.

O que essa cena nos indica são os mecanismos de poder que controlam e regulam nossas vidas e nossa relação com a diferença e os diferentes. No shopping, templo também (e não por acaso) da normalidade e ícone da vida contemporânea, tais mecanismos tornam-se ainda mais evidentes. E mais: além do tempo e da história, estes mecanismos atravessam os espaços para além dos manicômios, participam e compõem a nossa vida. Assim, facilmente identificamos os "homens de lata" nas figuras dos internos institucionalizados e medicalizados que passeiam inusitadamente num shopping, mesmo fora dos muros hospitalares. Mas, também é possível perceber nessa mesma cena - ainda que não tão facilmente - a presença sutil, intensa e cotidiana da lógica manicomial capturando os desejos dos passantes no shopping e convertendo-os em "homens de lata", insensíveis e impermeáveis à alteridade, tão aprisionados que estão em suas necessidades de consumo e homogeneização. Pelo consumo, cada um mais igual aos outros constrói para si as amarras quase invisíveis da recusa à diferença.

Porém, como essa lógica opera em nossas vidas de modo a sustentar a face crítica da loucura-doença mental e a reproduzir os manicômios (os visíveis e os não tão visíveis) entre nós? Os mecanismos de poder que mantém essa lógica hoje são os mesmos que fundam e sustentam os manicômios e a psiquiatria clássica? Eles operam em relação ao processo de desinstitucionalização e à própria luta antimanicomial?

\section{CENA DOIS: AINDA SE LUTA EM FAVOR DOS HOSPITAIS PSIQUIÁTRICOS!}

Andando pelas ruas bem próximas ao principal manicômio local, encontramos no cruzamento de duas grandes avenidas da cidade cartazes colados em muretas com a seguinte frase estampada em letras garrafais pretas e vermelhas: "Loucura? Loucura é a falta de leitos psiquiátricos!" (SINDICATO DOS MÉDICOS DO ESTADO DO RIO GRANDE DO SUL, 2007). Descobrimos que os cartazes eram propaganda de um movimento iniciado no Rio Grande do Sul, pelo Sindicato dos Médicos desse Estado (SIMERS), e apoiado pela Associação Brasileira de Psiquiatria $(\mathrm{ABP})$ contra a política de saúde mental que visa à redução progressiva de leitos em hospitais psiquiátricos, sob o argumento de desassistência aos portadores de transtornos mentais que esta política estaria produzindo. ${ }^{6}$ 
Com base nessa cena é possível fazer uma constatação: a luta em favor dos hospitais psiquiátricos ainda é uma realidade! E mais: essa luta facilmente dissemina-se pelo país e vai progressivamente ganhando forças, poderosamente ganhando recursos da rica máquina industrial-farmacêutica-hospitalar, sutilmente entrando em nosso cotidiano, espalhando-se pela cidade. De modo insuspeito, os cartazes figuram em diferentes cantos da cidade, os seus idealizadores invadem a televisão, associam-se a entidades e organizações de amigos, familiares e usuários no campo da saúde mental e, com base em argumentos "humanitários", desqualificam a rede de serviços substitutivos ou a qualificam de insuficiente e incompetente em nome de uma "reforma psiquiátrica". Resquícios pinelianos entre nós.

Tal constatação, dentre tantas outras possíveis em nosso cotidiano, nos faz concordar com Rodrigues (2007) quando, analisando o movimento brasileiro de desinstitucionalização e sua configuração no período de redemocratização na década de 1980, afirma:

É inegável, todavia, que durante o mesmo período, com prolongamentos até o presente, mantém-se uma vigorosa defesa, por parte de setores outros, de variadas formas de enclausuramento da loucura, a um ponto tal que nos levaria a afirmar, caso a problemática aqui abordada fosse diferente, que tanto ou mais do que uma luta antimanicomial, temos desenvolvido no Brasil, um árduo processo de anti-luta manicomial" (RODRIGUES, 2007, p. 55, grifo do autor).

Essa afirmação nos conduz à pergunta: como, então, caminha o movimento de luta antimanicomial brasileiro inspirado nas proposições basaglianas de desinstitucionalização? A referida constatação nos indica dois caminhos de análise decorrentes um do outro. Um deles é aquele relativo aos argumentos que sustentam essa anti- "luta manicomial" de modo que possamos identificar quais são os mecanismos utilizados e como atuam as forças instituídas representadas por movimentos como esse em favor dos leitos psiquiátricos que ganham espaço e operam cotidianamente por campanhas similares. Esse percurso analítico está necessariamente vinculado à análise dos limites e problemas que a luta antimanicomial brasileira enfrenta, de modo a dar espaço para uma "anti-luta manicomial".

Outro caminho de análise é aquele que procura refletir sobre a potência da luta antimanicomial, indicando para o que devemos estar atentos nessa luta e quais os rumos que ela pode tomar considerando o panorama da nossa sociedade atual. Ou seja, para o que devemos estar atentos e contra o que resistir quando nos implicamos em lutas por uma sociedade livre e justa, como é o caso da luta antimanicomial, em que a saúde possa representar a construção de possibilidades de vida para todos e cada um na sociedade contemporânea?

Considerando o primeiro caminho de análise, podemos indicar que o referido movimento em favor dos leitos psiquiátricos sustenta-se em mecanismos biopolíticos que, na sociedade contemporânea, são potencializados pelo argumento do risco e do medo tão presentes atualmente. Periculosidade, contágio, 
marginalidade, exclusão. Eis o que representa a loucura "desassistida" nessa lógica do biopoder. Na sociedade contemporânea, como afirma Rodrigues (2007, p. 58), "os riscos devem ser calculados: alienado o louco não mais d'A Razão (ou d'A Verdade), mas de Sua (Humana, demasiado humana) Verdade [...] posso me reconhecer nele, decerto, mas como risco, jamais como invenção/criação de outros mundos possíveis".

Assim, não é pela saúde dos "loucos" enquanto construção de possibilidades de vida livre que se luta nesse "movimento manicomial", mas para minimizar o risco de ter os "loucos" na rua, desassistidos, "perturbando" a cidade. No entanto, percebemos que se luta menos para afastar a loucura-doença mental do que para esconder e excluir a face da miséria e da pobreza que os loucos revelam. Ou seja, o que perturba o shopping e exige vigilância parece ser menos a "doença mental", do que a miséria daquelas pessoas que caminham mal vestidas e comem como "loucos" as fartas guloseimas ali ofertadas no templo do consumo. Nesse contexto, o hospital psiquiátrico continua, desde o século das luzes, a cumprir sua função social de manter a invisibilidade do binômio pobreza-loucura, mercantilizando a loucura que "com a pobreza e a ociosidade, doravante surge, de modo seco, na dialética imanente dos Estados", como alertou Foucault (1978, p. 63). Por isso, luta-se pela manutenção da velha aliança com o Estado no controle social da pobreza. Luta-se pelo aumento do número de leitos psiquiátricos e consequente manutenção do lucrativo aparato institucional psiquiátrico que têm sido hoje alvo da política pública de desospitalização e ampliação de uma rede substitutiva. Dessa forma, o hospital psiquiátrico e seus leitos figuram ainda (e como figuram!) na realidade brasileira como principal locus da assistência aos portadores de transtornos mentais, aos pobres perturbados de toda ordem, respondendo a demandas que vão muito além da clínica, mas que são sociais, culturais e econômicas. Esse argumento é reforçado quando consideramos que há hoje no Brasil cerca de 12.600 pessoas literalmente morando nos hospitais psiquiátricos, o que representa $30 \%$ do total de leitos psiquiátricos existentes (FURTADO, 2006). Isso equivale a dizer que $30 \%$ da demanda de leitos psiquiátricos em nosso país são, sobretudo, de moradia e alimentação.

Pensando nas conquistas concretas da luta antimanicomial, sabemos que no processo de desinstitucionalização brasileira há uma política efetiva de redução de leitos psiquiátricos que tem conseguido avançar nos últimos 20 anos, de tal modo que dos mais de 72.000 leitos em 1996, contamos no final de 2008 com 39.797 leitos em 214 hospitais (MINISTÉRIO DA SAÚDE, 2008).

No entanto, quando consideramos o número de leitos psiquiátricos ainda existentes, percebe-se que a oferta atual de mais de 1.300 Centros de Atenção Psicossocial (CAPS), distribuídos nas cinco regiões do país (MINISTÉRIO DA SAÚDE, 2008), por exemplo, ainda é insuficiente para atender a toda a demanda no campo. Assim, enquanto a rede substitutiva não oferece cobertura suficiente para tal demanda, contra-forças à luta antimanicomial operam, ganham visibilidade (e poder) e multiplicam-se em campanhas como aquelas da cena dois que enfraquecem o processo de desinstitucionalização. 
Diante dos mecanismos biopolíticos atuais que sustentam e operam nesta "anti-luta manicomial", a resistência não pode ser pensada como focada na ampliação de serviços substitutivos para dar conta da cobertura assistencial. Ela precisa operar na complexidade e flexibilidade desses mecanismos na vida, tendo em vista que "a superação das instituições de violência é uma exigência ética, técnica, política e cultural” (BASAGLIA, 1985, p. 49).

$\mathrm{Na}$ contemporaneidade, os mecanismos de biopoder ganham outras configurações e dirigem-se aos modos de subjetivação e à própria noção vida. Assim, no "passeio dos loucos ao shopping" não estão presentes apenas os mecanismos disciplinares e biopolíticos regulamentares da psiquiatria, mas toda uma micropolítica da vida cotidiana operando por meio de mecanismos biopolíticos para os quais devemos estar atentos na luta antimanicomial.

Deleuze (1992, p. xx) sugere que o "poder sobre a vida" encontra-se diluído hoje na chamada "sociedade mundial de controle", através do cruzamento entre a norma da disciplina e a norma da regulamentação, produzindo outros mecanismos de poder. Segundo Romagnoli et al. (2008) esse tipo de sociedade surge depois da Segunda Guerra Mundial, como mutação do capitalismo, e sustenta-se na crise das instituições disciplinares, o que conduz à configuração e à implantação de um novo modo de dominação.

Para Guattari e Rolnik (1986), tudo o que é produzido pela "subjetivação capitalística" e que nos chega pela linguagem, pela família e pelos equipamentos que nos rodeiam, não é apenas uma questão de transmissão de significações, mas também de sistemas de conexão direta entre as grandes máquinas produtivas e de controle social (como a mídia, por exemplo) e as instâncias psíquicas que definem a maneira de viver e perceber o mundo numa lógica de massificação e homogeneização das subjetividades. Assim, o que fica evidente no passeio dos loucos ao shopping para nós é a massa homogênea dos consumidores que deixa a diferença escancarada, ainda mais explícita, entre os loucos não consumidores e os consumidores "normais". Numa perspectiva micropolítica de olhar, poderíamos dizer que os loucos escapam a tal homogeneização, seja pela institucionalização que os homogeneizaram em outro sentido, seja pela simples resistência da loucura em conformar-se a padrões.

Nesses processos de subjetivação, os nossos desejos são alvo dessa lógica homogeneizante e manicomial reproduzindo em nós sutil e cotidianamente a opressão, o controle e a dominação, caracterizando-se como "desejos de manicômios" (MACHADO; LAVRADOR, 2001, p. 46). Dessa forma, percebemos que a lógica manicomial envolve-nos a todos, dentro e fora dos hospitais psiquiátricos, de tal modo que "as novas modalidades terapêuticas, tais como os serviços substitutivos, não garantem por si só a superação desse desejo de exclusão e de exploração que carregamos" (ALVERGA; DIMENSTEIN, 2006, p. 301). Ou seja, implementar uma política de desospitalização não conduz necessariamente a um processo de desinstitucionalização enquanto resistência à lógica manicomial e a tudo que ela representa nos diferentes campos em que opera no cotidiano. 
Nessa direção, podemos afirmar os desejos de manicômios têm lugar no cotidiano das relações entre moradores e equipe de cuidadores do SRT e na própria circulação dos moradores na cidade. Formas de controle que se apresentam nas práticas de cuidado burocratizadas, que impõe certas rotinas de atividades no sentido de ocupar os moradores e reproduzem certos padrões relativos, por exemplo, ao que devem vestir e a como devem comer.

Desejos de manicômios que se atualizam na fixidez dos roteiros de circulação pela cidade (casa-CAPS; casa-posto de saúde, casa-shopping, etc.). Mas, em cada passeio, curiosamente, os moradores propõem desvios de rota. A ida ao CAPS ou ao posto de saúde pode levá-los a outros roteiros possíveis que os conduzem a cortar o cabelo ou a, simplesmente, ficar conversando com "flanelinhas" na rua. Cotidianamente, os moradores convocam outros roteiros, exigindo outras práticas de cuidado menos tutelares e manicomiais e, assim, outras estratégias de sociabilidade possíveis vão sendo construídas na cidade.

Podemos afirmar, então, a partir de experiências como essas da vida cotidiana dos moradores na circulação pela cidade, que há uma dispersão dos mecanismos biopolíticos na sociedade atual que conduzem ora ao aprisionamento, ora à liberdade. De acordo com Pélbart (2003) e Romagnoli (2007), o termo biopolítica, tal como proposto por Foucault (1988), sofre um deslocamento de ordem conceitual e política na concepção de Hardt e Negri (2005). Nesse deslocamento, o termo biopolítica articula-se à própria noção de vida, deixa de ser prioritariamente a perspectiva do poder e de sua racionalidade sob o objeto passivo da vida das populações e "passa a designar potência de vida, tanto para ser explorada, serializada, homogeneizada, como para atuar como resistência" (ROMAGNOLI, 2007, p. 99). A vida deixa de ser definida apenas por processos biológicos que afetam a população e passa a ser entendida como inteligência, afeto, cooperação, desejo. Assim, de sua "acepção predominantemente biológica, ganha uma amplitude inesperada e passa a ser definida como poder de afetar e ser afetado" (PÉLBART, 2003, p. 25).

Assim entendida, essa "potência da vida" seria a sua própria capacidade de diferir, de variar, que operaria tanto quanto sua tendência à reprodução e à captura na dispersão. Biopoder e resistência lançam mão das mesmas estratégias, relativas aos espaços micropolíticos nos quais a vida é capturada e também ganha força, é inventada. Dessa forma, mediante esses novos mecanismos do biopoder dispersos, não cabe pensar a resistência apenas como negação ou oposição às forças em jogo, mas como a própria invenção da vida.

Como nos sugere Alarcon (2005), a micropolítica opera enquanto uma "luta contínua, perene, que se faz resistindo aos poderes miúdos, isto é, diferentes daqueles que se concentram nas formas jurídicas do Estado, mas que o sustentam de forma sub-reptícia na trama das pequenas relações do dia-a-dia" (ALARCON, p. 253-254). Assim, é a partir das micropolíticas na cidade, tal como na luta diária entre a loucura e o manicômio, que se podem vislumbrar transformações de ordem macropolítica. Como aponta Pélbart (2000, p. 27), o poder de criar, administrar e controlar a vida, aqui entendido sob a forma da lógica manicomial, 
[...] não vem só de cima, do Estado, ou da governamentalidade. É preciso admitir que acontece também “embaixo": esse poder de criar e promover vida [...] é exercido por todos e qualquer um, sobretudo num momento de economia imaterial em que mais e mais a produção se estende a serviços e requerem e formatam subjetividade.

Assim, a estratégia macropolítica da luta antimanicomial em si é insuficiente por que facilmente pode reduzir a desinstitucionalização a um mero deslocamento de território do manicômio, do hospital para os serviços substitutivos quando não atenta para os mecanismos da lógica manicomial em seus efeitos de serialização e estrangulamento da vida. Nesse contexto, ela pode reproduzir modos de trabalho burocratizados e conformado-conformadores que se restringem aos espaços dos serviços mesmos, impedindo que a criatividade e a invenção tenham lugar.

No entanto, na perspectiva biopolítica, a luta (micro) política consiste em resistir ao império da Razão no fazer cotidiano dentro e fora dos serviços de saúde, nos espaços de trabalho, de formação, de circulação na cidade, na luta pelo "direito à desrazão" (PÉLBART, 1990, p. xx ). Trata-se de, assumindo a presença sutil e capilar do manicômio em nós, a ele resistir. Trata-se, ainda, de resistir, na cidade, ao paradigma moderno que se fundamenta nos princípios de igualdade, fraternidade e liberdade no sentido da concessão de direitos e que se reproduz nos espaços de formação profissional em conformações tecnológicas baseadas nos humanismos dos "homens de boa vontade" que tutelam, argumentando em favor do cuidado, e reduzem as subjetividades a "indivíduos" limitados em suas possibilidades de saber, desejar, viver. Eis o que as experiências do SRT nos convocam a pensar quando, numa reunião entre técnicos e moradores, um dos moradores diz para os técnicos: "Sei que vocês têm boa vontade, mas não quero que vocês tenham pena de mim. Sou cidadão e quero só que vocês me acompanhem porque essa cidade é grande demais!"

E, nessa "cidade 'grande demais", é preciso resistir ao princípio humanitário de reabilitar socialmente aqueles que estão marginalizados, culpabilizando-os e desqualificando-os como sujeitos "ainda não" sociais (em busca de cidadania). A luta pela emancipação da vida, como afirmam Alverga e Dimenstein (2006), não se resume a uma luta por direitos e cidadania como concessões inventadas pela modernidade e que são insuficientes para aqueles que colocam em questão justamente o nosso modo de se organizar socialmente em que não há lugar para a diferença, as singularidades e a multiplicidade que a vida pode ter. É preciso, então, resistir à cidade homogênea, conformadora, locus da habilitação social conformadora. Mas como? Por que vias?

Ao acompanhar a experiência do SRT junto à equipe técnica e moradores, observamos que no processo de desospitalização e reabilitação psicossocial as práticas tutelares vão dando lugar a práticas que permitem os "desvios de rota" e vão caracterizando a presença dos cuidadores menos como vigilantes e mais como acompanhantes. Isso é possível, no entanto, quando há um trabalho de construção de responsabilidades compartilhadas entre gestão-serviço-moradores. 
Percebemos que a tessitura de diferentes redes de sociabilidade na cidade e de uma rede de responsabilidades que não "sobrecarregue" um ou outro ponto da rede substitutiva é indispensável na construção da vida livre para os moradores.

Isso fica evidente quando consideramos, por exemplo, um episódio real em que um dos moradores, com idade de cerca de 60 anos, no costumeiro trajeto que já realizava sozinho entre o SRT e o CAPS, "erra" o caminho, perde-se na cidade e fica desaparecido por três dias. As equipes do SRT e do CAPS movimentam-se num jogo de culpabilização no qual emergem queixas de falta de apoio por parte das técnicas do SRT, tentativas de explicar o desaparecimento e busca pelo morador. Nas iniciativas de busca dão-se conta da "rede" potente existente na cidade. A equipe do SRT contata diferentes pessoas do bairro que conheciam o morador e descobrem que este havia seguido um caminho diferente (numa outra direção da cidade) e que parecia meio "desorientado", de acordo com o relato desses conhecidos. A equipe do CAPS, por sua vez, aciona a polícia para ajudá-los na busca e, junto com a gestão da coordenação municipal de saúde, consegue que a mídia local veicule a notícia de desaparecimento do morador. No terceiro dia recebem um telefone de uma família, de uma cidade próxima, que, após assistir o jornal local pela TV, havia reconhecido o morador que havia acolhido, após encontrá-lo desmaiado e com muitas feridas nos pés de tanto caminhar. Ao buscá-lo, as equipes descobrem também que, de fato, o morador havia ficado desorientado (possivelmente, por dificuldades próprias da idade, aliadas aos efeitos adversos do medicamento que tomava) e que, na circulação "errante" pela cidade, diferentes encontros se processaram. Encontros com pessoas que lhe roubaram os chinelos e o dinheiro que levava. Encontros com pessoas indiferentes aos seus pedidos de ajuda e que nada fizeram. Encontros com pessoas que o alimentaram e cuidaram, possibilitando sua sobrevivência na cidade e o retorno ao SRT.

Depois desse acontecimento, as equipes avaliaram que deveriam sustentar a conquista da ida dos moradores ao CAPS sem que necessariamente um dos técnicos os "vigiasse" sempre. Por outro lado, ficou evidente como a circulação ainda restrita dos moradores pela cidade dificulta sua apropriação do espaço urbano, a ponto de desconhecerem os trajetos, as pessoas e a lógica de funcionamento da cidade, bem como o desconhecimento das pessoas em geral na cidade acerca da existência dessas pessoas "diferentes", possibilita acontecimentos dessa ordem. Assim, episódios como esse podem servir de analisador do cuidado operado, de modo que as equipes percebam como o compartilhamento de responsabilidades entre elas e a utilização de mecanismos de articulação e comunicação com outros atores e setores da cidade podem viabilizar o cuidado para além dos serviços, sem incorrer em negligência. Além disso, ficaram ainda mais evidentes para as autoridades envolvidas os possíveis problemas gerados pela não identificação do morador por documentos, fruto das dificuldades nas relações intersetorias (saúde-justiça) para a emissão de segundas vias, já que os anos de internação os destituíram de qualquer tipo de registro civil. Num mesmo acontecimento, portanto, as fragilidades e potencialidades da experiência se evidenciam, manicômios e resistências operam. 


\section{Considerações Finais}

A partir da análise de episódios como os relativos ao SRT, é possível pensar nos movimentos de resistência na perspectiva biopolítica contemporânea como "lutas em rede", tal como propõem Hardt e Negri (2005, p. 116). Para tais autores, os mecanismos de poder atuam sobre a vida hoje através de redes flexíveis, moduláveis e flutuantes - ampliando seu alcance, penetração, intensidade e capacidade de mobilização e conversão das subjetividades - e seria por esse mesmo caminho que a resistência deve operar. Tais lutas em rede seriam possíveis por meio do que chamam de "inteligência do enxame" (HARDT; NEGRI, 2005, p. 130), ou seja, da capacidade de infiltração, mobilização e articulação infindáveis, extensas e intensas a um só tempo, dos mais diversos agentes criativos.

Com base nessas ideias, a resistência no campo da saúde mental seria possível com a construção de redes na cidade e pela cidade. Ou seja, a ampliação das vias de comunicação, cooperação e criatividade entre serviços, gestores, profissionais, usuários, familiares, amigos e atores sociais em geral, configurando redes efetivas e afetivas de trabalho e sociabilidade, seria a principal via de resistência. O episódio acima nos indica como o uso de uma "inteligência coletiva" produzida nessas redes, construídas com e entre tais instâncias e atores, vai micropolítica e inventivamente produzindo estratégias e formas de superação dos manicômios erigidos a cada dia. A construção de diferentes instâncias de comunicação produzidas na cidade possibilitou a mobilização das pessoas na reconstrução do trajeto percorrido pelo morador a fim de encontrálo, assim como no seu próprio reconhecimento pelas pessoas que o acolheram. Do mesmo modo, cotidianamente, as pessoas que circulam nas proximidades do SRT ofertam, de diferentes formas, ao mesmo tempo, solidariedade e indiferença. Uns colaboram e montam junto com eles festas em datas comemorativas, enquanto outros desconhecem quem reside naquele lugar.

O que a experiência dos SRTs têm demonstrado, portanto, é que, entre a solidariedade e a indiferença, o processo de desinstitucionalização pode ser potencializado quando na relação loucura-cidade redes de sociabilidade, de afeto e cuidado são desenvolvidas e viabilizadas a partir de "lutas em rede". Redes tecidas numa costura macro e micropolítica, no campo da saúde - nas articulações entre gestão-serviços-comunidade - e para além dele nas articulações da saúde com outros setores (educação, habitação, assistência social, justiça etc.). Na vida social e cotidiana as articulações dos moradores e usuários podem gerar iniciativas de cooperação e solidariedade. É, portanto, nos espaços coletivos potencializados na cidade que "lutas em rede" podem se operar resistindo aos manicômios e produzindo a emancipação da vida. Nesse sentido, concluímos que em cada um dos encontros da loucura com a cidade, nos quais existem vidas em produção, podemos intervir como "trabalhadores militantes autopoiéticos" em cada uma das cenas urbanas que se produzem cotidianamente (MERHY, 2003, p. 13). Ou seja, acreditamos que é preciso resistir afirmativamente nos espaços da cidade e 
de construção coletiva, nos quais a potência que a vida tem de produzir vida e novos sentidos para ela pode se atualizar, de modo que possamos interferir nessas cenas cotidianas, entrar efetivamente nelas e não paralisar.

\title{
Notas
}

\begin{abstract}
${ }^{1}$ Referimos-nos à Tese de Doutorado (AMORIM, 2008) defendida pela primeira autora e orientada pela segunda.

${ }^{2} \mathrm{Na}$ clássica história do Mágico de OZ, de Lyman Baum (2006[1900]), que ficou famosa com o filme de Walt Disney, uma menina chamada Dorothy, perde-se num lugar encantado a procura do mágico que a levaria de volta para casa e encontra, entre outros personagens, um homem de lata que curiosamente "sofria" por não ter coração e, por isso, a acompanha na busca do mágico que poderia dar-lhe um coração.

${ }^{3}$ Tal expressão "forma-Homem" é utilizada por Deleuze (1988, p. 139) para diferenciar a relação da sociedade com a igreja conformada na figura da "forma-Deus" e a relação da sociedade com a ciência na qual emerge a figura da "forma-homem" na modernidade a partir dos princípios iluministas.

${ }^{4}$ Obviamente, existem outros condicionantes que marcam as diferenças entre o contexto europeu do brasileiro que não é nossa intenção tratar diretamente aqui. O que queremos destacar é que, no Brasil, o primeiro hospital psiquiátrico é inaugurado na segunda metade do século XIX, quando na Europa o regime disciplinar e as instituições em que ele opera datam ainda do século XVII. Assim sendo, o hospital psiquiátrico surge no Brasil como uma instituição disciplinar, mas que é configurada dentro de uma lógica biopolítica a partir de demandas de ordenamento das populações e cidades no século XVIII.

${ }^{5}$ A., técnica da SMS, em entrevista no dia 24/01/2007.

${ }^{6}$ Desde que o movimento foi lançado em julho de 2007, várias notícias foram veiculadas na mídia (ver em Jornal O Globo de 9/12/2007 e site da ABP, notícia de 29/02/2008, por exemplo) e o referido movimento vem ganhando adeptos (tais como os Conselhos Regionais de medicina e a Associação Brasileira de Usuários do SUS), assim como opositores (como os Conselhos Federal de Psicologia e suas regionais) em todo o país.
\end{abstract}

\section{REFERÊNCIAS}

AGEGGE, S. "Sem hospícios, morrem mais doentes mentais". In: $O$ GLOBO - Edição: 9/12/2007, Impresso: 8/12/2007 - 10: 35 h, p. 14. Disponível em: $<$ http://www.abpbrasil.org.br/newsletter/rep_oglobo $>$. Acesso em: 10/06/2009.

ALARCON, S. Da reforma psiquiátrica à luta pela vida não-facista. História, Ciências, Saúde. Rio de Janeiro, v. 12, n. 2, p. 249-263, ago. 2005.

ALVERGA, A. R.; DIMENSTEIN, M. A reforma psiquiátrica e os desafios na desinstitucionalização da loucura. Interface-Comunicação, Saúde, Educação. Botucatu, v. 10, n. 20, p 299-316, 2006.

AMARAnTE, P. (Org.). Psiquiatria Social e Reforma Psiquiátrica. Rio de Janeiro: Fiocruz, 1994.

AMORIM, A. K. A. O Serviço Residencial Terapêutico: cartografias de um híbrido no contexto da desinstitucionalização em saúde mental. 2008. Tese (Doutorado)Universidade Federal do Rio Grande do Norte, Natal, 2008. 
ASSOCIAÇÃO BRASILEIRA DE PSIQUIATRIA. ABP lança campanha pela criação de leitos. Notícia de 29/02/2008. Disponível em: <http://www. abpcomunidade.org.br/agencia_noticias/index.php?pg=12.> Acesso em: 10/09/2009.

BASAGLIA, F. A instituição negada. Rio de Janeiro: Graal, 1985.

. Loucura/Delírio. In: Escritos selecionados em saúde mental e reforma psiquiátrica. Rio de Janeiro: Garamond, 2005a. p. 259-298.

. Um problema de psiquiatria institucional: a exclusão como categoria sociopsiquiátrica. In:_Escritos selecionados em saúde mental e reforma psiquiátrica. Rio de Janeiro: Garamond, 2005b. p. 35-59.

BAUM, L. F. O Mágico de $O z$ (1900). Tradução e adaptação: Paulo Mendes Campos. Rio de Janeiro: Ediouro, 2006.

DELEUZE, G. Foucault. São Paulo: Brasiliense, 1988.

. Conversações. Rio de Janeiro: Editora 34, 1992.

FOUCAULT, M. História da Loucura na Idade clássica. São Paulo: Perspectiva, 1978.

. Microfísica do Poder. Rio de Janeiro: Graal, 1981.

. História da Sexualidade: a vontade de saber. Rio de Janeiro: Graal, 1988.

. Em defesa de uma sociedade. São Paulo: Martins Fontes, 1999.

. Problematização do sujeito: Psicologia, Psiquiatria e Psicanálise. Rio de Janeiro: Forense Universitária, 2006. Coleção Ditos \& Escritos, v. 1.

FURTADO, J. Avaliação da situação atual dos serviços residenciais terapêuticos no SUS. Ciência \& Saúde Coletiva, Rio de Janeiro, v. 11, n. 3, p. 785-795, jul./ set., 2006.

GUATTARI, F.; ROLNIK, S. Micropolítica: cartografias do desejo. Rio de Janeiro: Vozes, 1986.

HARDT, M.; NEGRI, A. Multidão, guerra e democracia na era do império. Rio de Janeiro: Record, 2005. 
MACHADO, L. R.; LAVRADOR, M.C. Loucura e subjetividade.In: MACHADO, L. R.; LAVRADOR, M. C; BARROS, M. E. (Org.). Texturas da Psicologia: subjetividade e política no contemporâneo. São Paulo: Casa do Psicólogo, 2001. p. $45-58$.

MERHY, E. E. A loucura e a cidade: outros mapas. Niterói, UFF, 2003. Disponível em: $\quad<$ http://www.uff.br/saudecoletiva/professores/merhy/indexados-21.pdf $>$. Acesso em: 1 jun. 2009.

MINISTÉRIO DA SAÚDE. Saúde Mental no SUS. Informativo da Saúde Mental, Brasília, DF, ano 6, n. 26, ago./dez. 2007. Departamento de Ações Estratégicas. Coordenação Geral de Saúde Mental.

. Saúde Mental em Dados: com dados para análise da rede em grandes cidades. Brasília, DF, ano 3, n. 5, out. 2008. Departamento de Ações Estratégicas. Coordenação Geral de Saúde Mental.

PÉLBART, P. Manicômio mental: a outra face da clausura. In: LANCETTI, A (Org.). Saúde Loucura. São Paulo: Hucitec, 1990. v. 2, p. 130-138.

. Direitos Humanos e Cyber-Zumbis. In: . A vertigem por um fio: políticas da subjetividade contemporânea. São Paulo: Iluminuras, 2000. p. 23-28.

. Poder sobre a vida, potências da vida. In: de biopolítica. São Paulo: Iluminuras, 2003. p. 19-27. . Vida Capital: ensaios

RODRIGUES, H. C. Michel Foucault, as marcas da pantera e a pantera corde-rosa: apontamentos sobre o processo de desinstitucionalização psiquiátrica. Vivência, Natal, n. 32, p. 41-60, 2007.

ROMAGNOLI, R. C. et al. Por uma clínica da resistência: experimentações desinstitucionalizantes em tempos de Biopolítica. Interface - Comunic., Saúde, Educação. Botucatu, 2008. Disponível em: <http://www.interface.org.br/ arquivos/aprovados/artigo77.pdf>. Acesso em: Pré-publicação

ROMAGNOLI, R. A invenção como resistência: por uma clínica menor. Vivência, Natal, n. 32, p. 97-108, 2007.

SINDICATO DOS MÉDICOS DO ESTADO DO RIO GRANDE DO SUL. Campanha SIMERS: Loucura é a falta de leitos psiquiátricos. Porto Alegre: 2007.

Recebido em: junho de 2009

Aceito em: agosto de 2009 